\title{
POSSIBILIDADES PEDAGÓGICAS DE FORMAÇÃO DO LEITOR CRÍTICO DE TEXTOS LITERÁRIOS A PARTIR DE UM JOGO DIGITAL PARA ALUNOS DO ENSINO MÉDIO
}

\author{
PEDAGOGICAL POSSIBILITIES FOR EDUCATING THE \\ CRITICAL READER OF LITERARY TEXTS BY MEANS OF A \\ DIGITAL GAME FOR HIGH SCHOOL STUDENTS
}

Rodrigo Alves dos Santos*

\begin{abstract}
Resumo: O objetivo central deste texto é apresentar possibilidades de intervenção pedagógica do professor de Língua Portuguesa formador de leitores críticos de textos literários, a partir de um jogo digital desenvolvido para colocar o estudante do Ensino Médio em contato com a produção literária e artefatos culturais relacionados ao poeta Ferreira Gullar, um dos mais representativos autores nacionais do século XX. Ao apresentarmos o jogo em causa e as opções feitas na sua construção, buscamos apontar o quão central é o papel do professor na promoção dos letramentos, vislumbrando possibilidades de aproximação entre a cultura literária e as tecnologias de informação e comunicação.
\end{abstract}

Palavras-chave: Formação de leitores. Promoção dos letramentos. Jogos digitais. Ensino Médio.

Abstract: The main objective of this text is to present possibilities of pedagogical intervention by the Portuguese language teacher who educate critical readers of literary texts from a digital game developed to put high school students in contact with literary production and cultural artifacts related to the poet Ferreira Gullar, one of the most representative brazilian authors of the 20th century. When presenting the game in question and the options made in its construction, we seek to point out how central the role of the teacher is in promoting literacies, envisioning possibilities of approximation between literary culture and Information and Communication Technologies.

Keywords: Education of Readers. Promotion of Literacies. Digital games. Brazilian High School.

\section{Contextualização}

As mudanças resultantes da passagem da antiga sociedade industrial para a sociedade da informação ou do conhecimento, na qual nos inserimos, estão, como se sabe, na raiz do entendimento do discurso internacionalmente divulgado de que o uso proficiente das Tecnologias da Informação e Comunicação (TIC) é uma das competências-chave para o século XXI (Cf. DELORS, 2001, 2005). Esse entendimento, por sua vez, está no cerne de outro, que veio sendo naturalizado no Brasil recente (não sem certa crítica, claro!), de que uma importante função da escola regular deveria ser a de formar as crianças e os jovens como utilizadores conscientes e críticos (portanto, proficientes) não só dessas tecnologias, mas também da cultura produzida e divulgada em torno delas.

Nessa perspectiva, a necessidade do uso das TIC nas escolas e, mais especificamente, nas salas de aula, é um argumento que vem sendo veiculado pelo discurso educacional oficial acerca das políticas públicas de educação básica de grande parte do mundo, não sendo diferente no Brasil. Reina, nesse discurso, a crença na

\footnotetext{
* Doutor em Educação pela FaE/UFMG. Professor de Língua Portuguesa, Literatura e Cultura do Departamento de Formação Geral do Centro Federal de Educação Tecnológica de Minas Gerais CEFET-MG - Campus Divinópolis. Docente do Programa de Pós-Graduação em Educação Profissional e Tecnológica - PROFEPT. E-mail: rodrigo.alves@ cefetmg.br
} 
possibilidade de que, com a incorporação das TIC nas estratégias pedagógicas escolares, haverá uma melhoria nos processos de aprendizagem, de pensamento e, inclusive, de representação/construção do conhecimento pessoal (JONASSEN; CAMPBELL; DAVIDSON, 1994; JONASSEN, 1997; JONASSEN, 2007). Esse é, inclusive, um argumento que vem extrapolando o universo da educação formal, pois acredita-se que o uso das TIC, se incorporado às práticas sociais, transforma a forma de viver do ser humano porque oferece outras maneiras de comunicação, produção e comercialização de bens e mercadorias, divertimento e educação.

Sob essa alegação e também a de que é função do Ensino Médio formar um leitor crítico de textos literários (BRASIL, 2006), os documentos reguladores da formação e da atuação dos professores de Língua Portuguesa nesse nível de ensino têm, paulatinamente, incorporado e divulgado o argumento de que um outro perfil de jovem egresso da educação básica (SANTOS, 2009; 2011, 2017a) vem sendo demandado pelos novos contextos socioeconômicos desenhados para o século XXI, o que inclui, claro, o domínio das tecnologias por meio das quais se produzem, se veiculam, se configuram certos modos de ler e de acessar a cultura literária.

Nesse contexto, considerando que o exercício profissional dos docentes que atuam nos espaços escolares vem se dando em um cenário confrontado continuamente com essas "novas demandas", temos assistido, conforme bem discutem Lepeltak e Verlinden (DELLORS, 2005, p. 207), a momentos de euforia e de desilusão da escola em relação às TIC. Fato que se soma com a constatação inconteste de que se vive, no Brasil e em parte do mundo, uma assumida crise de identidade e de finalidade da etapa do ensino regular que antecede a entrada de estudantes, em sua maioria jovens, nos cursos de nível superior (BACHA; SCHWARTZMAN, 2011).

Nesse painel de complicações para inserção das TIC nas práticas pedagógicas dos professores, mais complexa ainda é a questão da incorporação delas no trabalho com a leitura literária a ser desenvolvido com os alunos que frequentam o Ensino Médio regular (SANTOS, 2017b). Isso porque se somam aos desafios de incorporação das TIC às estratégias pedagógicas as declaradas dificuldades que a escola de nível médio tem para desenvolver formas de abordar o texto literário que resultem na formação de leitores críticos de textos literários, desejada pelas instâncias reguladoras da educação formal do país. Assim, para além da reconhecida fragilidade dos cursos de formação de professores para atuação na educação básica brasileira de um modo geral (DINIZPEREIRA, 1999, 2006) e da formação do professor de Língua Portuguesa do Ensino Médio em particular (GALVÃO; SILVA, 2017), a abordagem do texto literário nos anos finais da educação básica brasileira tem esbarrado em problemas crônicos como o predomínio de uma perspectiva meramente historiográfica, a ênfase na resolução de questões de vestibular (agora mescladas às questões do Exame Nacional do Ensino Médio - ENEM) e a redução da leitura da literatura à legitimação de interpretações canônicas de conhecidos trechos de textos em verso e prosa (COSSON, 2014; PINHEIR, 2006; LEAHY-DIOS, 2000).

Considerando todo o cenário acima sumarizado, um desafio premente para os interessados na superação desse quadro de dificuldades é promover uma aproximação entre os jovens frequentadores do Ensino Médio e a cultura literária produzida em torno de autores e obras centrais para se pensar o Brasil e sua cultura. Buscando contribuir para a realização dessa tarefa, o presente texto vem apresentar um exemplo de um jogo digital desenvolvido no âmbito de projetos de pesquisa e de inovação tecnológica realizados no câmpus Divinópolis do Centro Federal de Educação Tecnológica de Minas Gerais - CEFET-MG, salientando o quão importante é o papel do professor de língua portuguesa na promoção dessa aproximação entre as culturas tecnológica e 
literária. Nosso objetivo é demonstrar, como sugere o título deste artigo, caminhos para se vislumbrar uma intervenção educativa que, aproximando a ação docente e o uso das TIC, permita aplicar a promoção dos letramentos e atender às expectativas em relação à formação de leitores de textos literários dos anos finais da educação básica brasileira.

\section{Demandas atuais para a formação de leitores de textos literários nos anos finais da educação básica brasileira}

Foi nos documentos reguladores dos anos finais da educação básica brasileira, publicados entre meados da última década dos anos 1990 e segunda metade da primeira década deste século XXI - Parâmetros Curriculares Nacionais de Língua Portuguesa do Ensino Médio (1999), PCN+ de Língua Portuguesa do mesmo nível de ensino (2002) e as Orientações Curriculares do Ensino Médio de Língua Portuguesa (2006) - que se deram, como já defendemos em outros momentos (SANTOS, 2009, 2014, 2017a), as bases da configuração do que hoje se espera do professor de Língua Portuguesa do Ensino Médio em relação à abordagem da literatura em contexto escolar de nível médio. De acordo com o discurso veiculado nesses documentos, é esperado que os docentes assumam, no que tange à formação literária do aluno dos anos finais da educação básica brasileira, o papel de formador de leitores críticos de textos literários.

Para desempenhar com competência essa função, o professor em causa deve, conforme argumentação oficial, ser "mais consciente sobre o público para o qual leciona - os jovens -, mais bem informado, atualizado, usuário competente das tecnologias, leitor não preconceituoso..." (SANTOS, 2014, p. 436), promovendo um deslocamento do antigo professor de literatura do $2^{\circ}$ Grau para o atual formador de leitores críticos de textos literários. Deslocamento este em que o docente passa, ainda, à condição de mediador de leitura, ou seja, "alguém que toma o texto como um monumento que precisa ser explorado, olhado, analisado, desconstruído se necessário" (BERTUCCI BARBOSA; VIEIRA BARBOSA, 2013, p. 11). Isso, claro, sem desconsiderar o potencial do mestre para ser um leitor mais experiente e, por isso, conduzir os processos de negociação dos sentidos de um texto (KOCH, 2009, p. 17), reconhecendo que também o texto tem seus direitos e impõe limites à interpretação (ECO, 2008).

Nesse movimento, que denominamos de reinvenção do professor de Língua Portuguesa dos anos finais da educação básica (SANTOS, 2009), engendrado pelo discurso veiculado nos documentos já referidos, ganha centralidade entre os fundamentos teóricos e metodológicos a serem dominados pelo formador de leitores críticos de textos literários, a perspectiva dos letramentos. Perspectiva esta que veio se capilarizando no país desde meados dos anos 1980, exercendo grande influência, inclusive, sobre o discurso regulador do ensino de Língua Portuguesa no país, como o veiculado nos Parâmetros Curriculares Nacionais e documentos dele derivados (SANTOS, 2009) outrora e, mais recentemente, na Base Nacional Comum Curricular (BNCC), na qual se enuncia explicitamente que:

Ao componente Língua Portuguesa, cabe, então, proporcionar aos estudantes experiências que contribuam para a ampliação dos letramentos, de forma a possibilitar a participação significativa e crítica nas diversas práticas sociais permeadas/constituídas pela oralidade, pela escrita e por outras linguagens. (BRASIL, 2018, p. 678). 
Nesse movimento de capilarização do termo, o substantivo letramento passou, principalmente na primeira década do século XXI, a receber diversas adjetivações que procuraram se referir a diferentes práticas sociais de leitura e de escrita, ora levando em consideração o suporte textual (p. ex. letramento digital), ora a esfera de circulação dos textos (p. ex. letramento literário), ora a intencionalidade dos autores (p. ex. letramento político), ora o alcance social proporcionado pelo domínio de certos artefatos produzidos em torno da cultura e das formas de materialização da linguagem (p. ex. letramento cultural).

Assim, avançando nas reflexões sobre a concepção de letramento literário que ele mesmo tem ajudado a fixar nos estudos sobre a abordagem do texto literário em contexto escolar, Rildo Cosson, mais recentemente, esclarece que:

Aqui o letramento é menos uma prática social da escrita do que um processo de construção dos sentidos que se efetiva individual e socialmente; e o literário deixa de ser aplicado apenas a um conjunto de textos, para ser reconhecido como repertório cultural constituído por uma grande variedade de textos e atividades que proporcionam uma forma muito singular - literária - de construção dos sentidos. [...] Pensado dessa maneira, o letramento literário não se restringe ao campo escolar, embora se reconheça o impacto da escola e da academia como instituição central na manutenção e reprodução de protocolos de leitura, sendo de sua responsabilidade o desenvolvimento sistemático da competência literária. (COSSON, 2015, p. 182).

Nesse âmbito, ao formador de leitores críticos de textos literários, cabe, na abordagem da literatura em contexto escolar, contribuir ${ }^{1}$ para a promoção de uma educação literária que leve o jovem que frequenta os anos finais da educação básica brasileira não só a se apropriar com plenitude dos objetos estéticos produzidos nessa esfera - a literária -, mas também de todo o patrimônio elaborado em torno desses objetos (LEAHY-DIOS, 2000; AZEVEDO; BALÇA, 2016). Isso se daria, por exemplo, por meio do desenvolvimento de uma capacidade de leitura crítico-reflexiva que permitisse ao discente/leitor (re)pensar o contexto sociocultural em que se inscreve e vislumbrar, para tal contexto, possibilidades de intervenção e reestruturação.

Ainda no âmbito das teorias dos letramentos, mais recentemente, no início desta segunda década do século XXI, que agora se finda, grande visibilidade vem sendo dada ao termo multiletramentos, levando os estudiosos do tema a falarem em uma pedagogia dos multiletramentos. Nessa abordagem, conforme elucidam Rojo e Moura (2012), o ato de ler envolve articular diferentes modalidades de linguagem além da escrita, como a imagem (estática e em movimento), a fala e a música. Nesse sentido, refletindo as mudanças sociais e tecnológicas atuais, ampliam-se e se diversificam não só as maneiras de disponibilizar e compartilhar informações e conhecimentos, mas também de lê-los e produzi-los. Tem-se, com isso, o desenvolvimento de linguagens híbridas que envolvem, por conseguinte, desafios para os leitores e para os agentes que

\footnotetext{
${ }^{1}$ Cabe destacar aqui, como bem fundamentam Leahy-Dios (2000) - no Brasil - e Azevedo e Balça (2016) - em Portugal - que a educação literária é uma tarefa coletiva, transversal e contínua que envolve família, educadores, professores e outros inúmeros agentes que atuam nos inúmeros espaços de formação que passam pela escola, mas não se restringem a ela. Daí, portanto, nossa opção pelo verbo contribuir, empregado nesta construção.
} 
trabalham com a formação de usuários competentes da língua, entre eles, a escola e os professores.

É nesse cenário, portanto, que os jogos digitais surgem como uma ferramenta de amplas possibilidades pedagógicas para auxiliar o professor de Língua Portuguesa que assume a sua condição de formador de leitores críticos de textos literários, na promoção de uma educação literária dos jovens que frequentam o Ensino Médio brasileiro. Isso porque, como já defendemos em trabalho recente (SANTOS; BECHELANE; SILVA, 2018), além de permitir incorporar às práticas pedagógicas escolares aparatos com grande potencial atrativo para jovens nativos digitais deste século XXI, os games possibilitam, ainda, que a ação docente absorva e operacionalize os pressupostos que a pedagogia dos multiletramentos demanda da configuração atual do ensino de Língua Portuguesa nos anos finais da educação básica brasileira. Tudo isso, porém, não implica, como veremos, a anulação da importância do professor no processo de formação do leitor crítico de textos literários, almejado ao final do Ensino Médio.

\section{Um exemplo de aproximação entre as culturas literária e tecnológica na formação de leitores críticos de textos literários no Ensino Médio}

Pensar uma aproximação possível entre a cultura literária e as TIC na formação de leitores críticos de textos literários no Ensino Médio não é algo comum em um país que, como já afirmado neste texto, ainda se vê às voltas com velhos dilemas que assolam a escolarização da literatura. Buscando evidenciar o quão possível é essa aproximação é que vem sendo desenvolvida no Laboratório de Atividades de Pesquisa e de Desenvolvimento Profissional Docente (LAPED) do câmpus Divinópolis do CEFETMG, uma série de projetos de pesquisa e de desenvolvimento tecnológico apoiados pela Fundação de Amparo à Pesquisa de Minas Gerais (FAPEMIG) e pelo Conselho Nacional de Desenvolvimento Científico e Tecnológico (CNPq). Nesse contexto é que foi desenvolvido o TURVO, ${ }^{2}$ um jogo digital com a finalidade de colocar alunos em contato com a produção literária do poeta Ferreira Gullar e com uma série de objetos estéticos elaborados a partir dessa produção. Logo, um ponto de partida para a construção do jogo em causa foi considerar não só os artefatos literários produzidos pelo autor, mas também todo um conjunto de obras, informações, produtos e materiais diversos criados em torno dos seus escritos ou a eles relacionados.

Inspirado nos clássicos jogos da memória analógicos, em que cartas convencionais eram postas com a face voltada para baixo e iam sendo desviradas aos pares por um ou mais jogadores, que deveriam esgotar o mais rápido possível o rol de cartas disponíveis, o TURVO demanda, basicamente, que o jogador proceda da mesma forma, porém em uma interface digital. Trata-se de um jogo desenvolvido para aparelhos de telefone móveis e que não depende da existência de conexão com a internet para ser jogado, devendo, apenas, ser baixado para o aparelho. O nome do aplicativo - TURVO - foi inspirado nas primeiras palavras do mais conhecido dos poemas de Ferreira Gullar, o "Poema Sujo", apresentadas nos versos: "turvo turvo/a turva/mão do sopro/contra o muro/escuro" (GULLAR, 2001, p. 03).

\footnotetext{
${ }^{2}$ Para o desenvolvimento do presente jogo, foram de grande relevância as atuações, como bolsistas e estagiários, dos estudantes Orlando Enrico Liz Silvério e Silva (UFMG), Lucas Augusto Niess Soares Fonseca (CEFET-MG Divinópolis), Laura Ferreira Santos (CEFET-MG Divinópolis) e Mário Vítor Kern Xavier (CEFET-MG Divinópolis).
} 
Já na seleção do nome do jogo, pensou-se na possibilidade de o docente que o utilize em suas aulas ocupar uma posição ativa. Desse modo, espera-se que o professor abandone a condição de mero expectador da tecnologia e, em oposição a isso, legitime o seu papel de mediador no processo de construção da compreensão leitora. Para tanto, na introdução da aplicação do TURVO como estratégia pedagógica em uma aula de Língua Portuguesa, o esperado é que o docente explore, por exemplo, uma série de perguntas que levem os aprendizes - e futuros jogadores - a entrarem em contato com uma das estratégias que autores como Duke e Pearson (2002) consideram essenciais ao processo da compreensão leitora: a predição.

O significado da estratégia de predição está no próprio radical da palavra, permitindo associação a predizer. Possibilita vincular também significativamente a previsão, a antecipação e até mesmo a adivinhação. Em relação a esta última, há que explicitar que não se trata de um procedimento impulsivo e aleatório. Consiste num procedimento em que o leitor, com base nas pistas linguísticas e nos seus conhecimentos prévios, faz importantes inferências. (PEREIRA; SANTOS, 2017, p. 365-366).

Partindo desses pressupostos, questões que abordassem o significado da palavra turvo, seus sinônimos e situações de uso, ou até mesmo a utilização de imagens e exemplos de emprego para além dos versos iniciais do poema, poderiam ser ações associadas ao momento inicial de trabalho com o aplicativo em questão. Desse momento de motivação (SOLÉ, 1998), partiria para a operacionalização de um percurso pedagógico cuja finalidade seria estimular o aluno/jogador para o uso de estratégias cognitivas e metacognitivas essenciais à compreensão leitora (KATO, 1985).

$\mathrm{Na}$ execução desse percurso pedagógico, contemplando a inserção das TIC nas práticas educativas escolares, algo fundamental é a superação do uso dos jogos da forma costumeira como eles vêm entrando no universo da sala de aula: ora como uma ferramenta meramente motivadora, ora como artefato exageradamente cultuado. É preciso, portanto, que um professor que acione instrumentos como o TURVO o faça como meio de favorecer a construção de um ambiente de aprendizagem no qual o aluno/jogador seja capaz de construir e ampliar seus conhecimentos por meio da interação com esses artefatos. A essas proposições, acrescenta-se o entendimento de que, no trabalho de formação de leitores em contexto escolar, o papel do docente, hoje, é muito diferente daquele que se cristalizou nos antigos contornos da escola regular (ANTUNES, 2001, p. 12). Desse modo, o esperado é que, quando do acionamento de jogos como o TURVO como recurso pedagógico no trabalho com a cultura literária dos anos finais da educação básica, não caibam posições autoritárias ou passivas aos professores e sim que estes assumam a sua condição de agentes letradores (BORTONIRICARDO; MACHADO, 2010), de mediadores (GERALDI, 2013; KLEIMAN, 1998, 2002; KOCH; ELIAS, 2007) na construção dos sentidos de um texto e da apreensão dos saberes assumida pelos mestres.

Considerando tais fundamentos, uma vez feitas as devidas intervenções com o alunado na apresentação do TURVO e na exploração do título do jogo, é chegada, finalmente, a hora de acessar o aplicativo. Nesse momento, é importante que o professor deixe que os alunos experienciem o aplicativo de forma intuitiva, autônoma, sem utilizá-lo, já de início, como instrumento de promoção de uma leitura crítica da produção de Ferreira Gullar e de todo o universo de artefatos produzidos em torno dela. Trata-se, aqui, de um momento de descoberta do jogo que pode, depois de um tempo de experimentações individuais e/ou em grupo, resultar em uma conversa em que as 
primeiras impressões do público-alvo sobre o que vivenciou serão alvo de registros e de reflexões.

Decorrido esse período de experimentação, temos, então, a etapa em que os elementos de composição do jogo serão explorados no processo de formação do leitor crítico de textos literários, quando muitas serão as possibilidades de intervenções do docente, como se verá. Assim sendo, ao acessar o jogo, o usuário entra em contato com uma interface que lhe apresenta um menu de opções organizado em forma de botões, como se vê na Fig. 1, apresentada a seguir.

Figura 1 - Interface inicial do Turvo

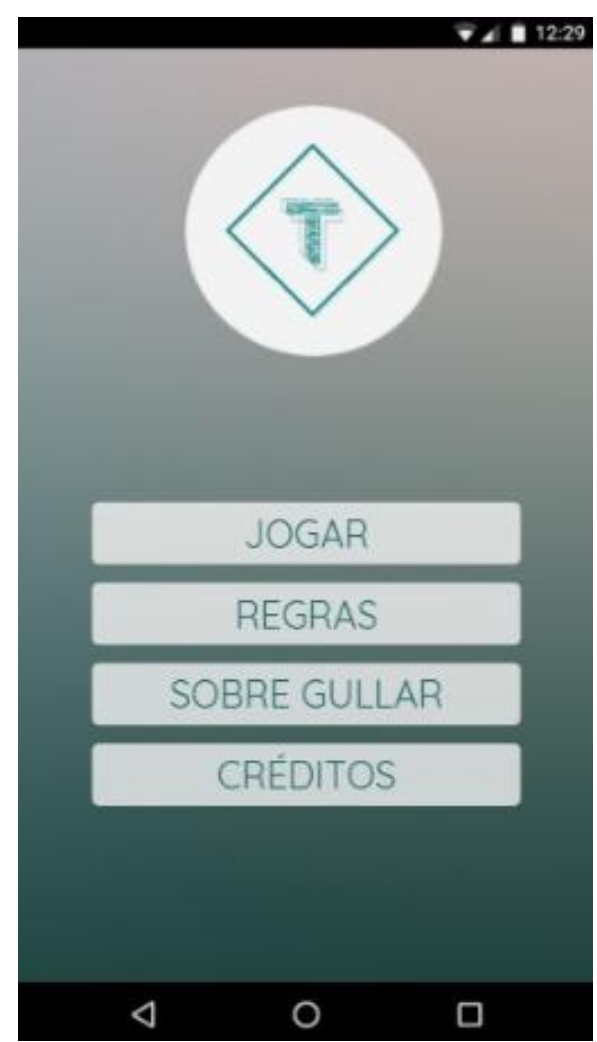

Fonte: acervo da pesquisa

Acessando esse menu, o usuário passa, imediatamente, a ouvir uma versão da composição "Trenzinho do Caipira", cuja melodia é do compositor brasileiro Heitor Villa-Lobos, e a letra consagrada é um trecho do "Poema Sujo", de Ferreira Gullar. Note-se que, como o nome do jogo, a canção que toca nesse primeiro contato do aluno com o game oferece uma oportunidade para que o formador de leitores críticos de textos literários possa, a partir de uma interação com os discentes, estimular uma conversa acerca da obra do poeta maranhense e de toda a produção cultural que a cerca. Para ampliar essas possibilidades é que foi pensado o item "Sobre Gullar", que apresenta não só uma biografia do autor, mas também uma breve apreciação crítica de sua obra, o que poderá ser explorado pelo professor na condução da apresentação da produção do poeta aos alunos jogadores. Se clicar no link "Regras", no "Sobre Gullar" ou nos "Créditos", a música "Trenzinho do Caipira" cessa imediatamente, sem que outro áudio se inicie.

Uma vez clicando em "Jogar", o aluno/jogador é encaminhado à tela com as cartas que deverá desvirar para formar pares do jogo da memória. Enquanto joga, o discente ouve o "Poema Sujo" sendo recitado na voz do próprio Ferreira Gullar, 
situação que possibilita com que os jovens entrem em contato com a voz do autor e com a interpretação do seu mais famoso texto. Esse elemento auditivo também possibilita, como se percebe, uma intervenção do docente, o qual poderá se ater ao fazer literário do escritor, explorando aspectos como tema, construções frasais e melódicas, modo de organização das estrofes... acompanhado ou não de uma versão impressa, que poderá estar disponível no livro didático ou em outro suporte. Estão dadas, também, com esse elemento do jogo, condições para que sejam exploradas, pelo docente, questões sobre os modos de ler um poema, as pausas, a respiração, os intervalos... tudo isso a partir da leitura do próprio autor.

O clique em "Jogar" dispõe as cartas de modo a não mostrarem sua face para o jogador. Supondo um usuário que esteja nos anos finais da educação básica e que domine os protocolos de leitura que já devem ser conhecidos por estudantes dessa etapa, o TURVO não faz como os jogos da memória convencionais, que mostram rapidamente como os pares de carta estão dispostos e o jogador já tem, ali, uma noção de localização. Nessa versão, o usuário deve ir identificando os pares de carta a partir do momento em que as visualiza. Dessa maneira, somente clicando em cada carta é que o jogador pode ir descobrindo, pouco a pouco, a localização dos pares no jogo como um todo, conforme sugere a Fig. 2.

Figura 2 - Disposição das cartas no jogo

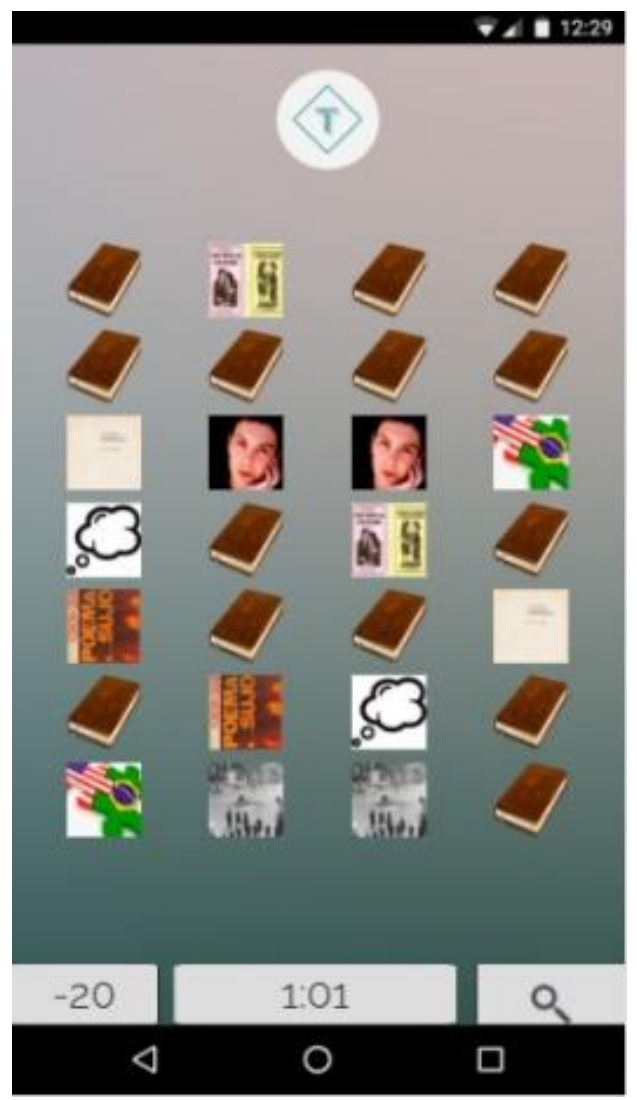

Fonte: acervo da pesquisa 
As imagens que compõem as "cartas" consistem em uma série de figuras relacionadas à contextualização histórico-social e à produção cultural que cerca a obra de Ferreira Gullar, conforme se vê no quadro a seguir:

Quadro 1 - Imagens utilizadas na composição das cartas do jogo TURVO

Imagem 01: Numa mesma imagem, bandeiras da União Soviética, Argentina e Chile; locais em que o autor viveu.

Imagem 02: São Luís/MA, cidade natal do poeta.

Imagem 03: Capa do livro A luta corporal, 1954 - $1^{\circ}$ livro do autor ( $1^{\text {a }}$ edição)

Imagem 04: Capas de cordel [Abertura para aludir à obra João Boa Morte]

Imagem 05: Conflito do governo militar brasileiro

Imagem 06: Cena do filme Cabra marcado para morrer

Imagem 07: Trecho do poema "Não há vagas", de Ferreira Gullar

Imagem 08: Capa do disco Antologia poética, de Ferreira Gullar

Imagem 09: Imagem do troféu do prêmio Jabuti

Imagem 10: Capa de "Poema Sujo", livro mais conhecido de Ferreira Gullar

Imagem 11: Um balão de memória [para ressaltar o quanto a memória é tema recorrente na poesia do autor]

Imagem 12: Imagem da cantora Adriana Calcanhotto

Imagem 13: Trecho do poema "Traduzir-se", de Ferreira Gullar.

Imagem 14: Imagem de um trenzinho caipira.

Associado a essas imagens, está um grande diferencial deste jogo da memória digital: as "Dicas". Trata-se de 28 informações que se referem a um amplo espectro de dados sobre a vida do autor, suas obras e a produção de outros artefatos culturais feita a partir do universo literário construído pelo poeta. Nota-se, portanto, que a opção pela inserção dessas "Dicas" no jogo se justifica por criar, com elas, condições para que o professor que estiver utilizando o game como ferramenta pedagógica possa acionar vastas possibilidades de interação dialógica por meio da exploração de informações sobre a obra do autor, sobre opções formais e temáticas adotadas pelo poeta, sobre a sociedade brasileira do contexto de produção ou, ainda, sobre todo um aparato artísticocultural produzido por meio de outras linguagens (música, cinema, etc.) que se apropriaram das referências geradas pelos escritos de Ferreira Gullar. Estão dadas, portanto, as condições para que a mediação docente possa, se assim o quiser, acionar a pedagogia dos multiletramentos, já mencionada no segundo tópico deste texto. $\mathrm{O}$ conteúdo das "Dicas" está apresentado no Quadro 2.

Quadro 2 - Dicas

\begin{tabular}{|c|l|}
\hline IMAGEM & \multicolumn{1}{c|}{ INFORMAÇÕES PARA LEGENDAS } \\
\hline \multirow{4}{*}{01} & $\begin{array}{l}\text { a) Durante o exílio, por causa dos excessos do Governo Militar, Ferreira Gullar viveu na } \\
\text { Argentina, Chile e Rússia (na época, União Soviética). }\end{array}$ \\
\cline { 2 - 2 } & $\begin{array}{l}\text { b) Buenos Aires, Santiago e Moscou são algumas das capitais de países do mundo para } \\
\text { onde artistas brasileiros, como Ferreira Gullar, foram exilar-se na época da ditadura } \\
\text { militar. }\end{array}$ \\
\hline \multirow{3}{*}{02} & $\begin{array}{l}\text { a) Capital do Estado do Maranhão, única cidade brasileira fundada por franceses. } \\
\text { b) Cidade de nascimento do poeta, o qual tem como conterrâneo outro escritor de poesias, } \\
\text { o romântico Gonçalves Dias. }\end{array}$ \\
\hline \multirow{3}{*}{03} & $\begin{array}{l}\text { a) Considerado o primeiro livro do poeta, A Luta Corporal é tomado como a obra } \\
\text { iniciadora do movimento paulista da Poesia Concreta. }\end{array}$ \\
\cline { 2 - 2 } & b) Nos poemas deste livro, o poeta "luta para transformar a palavra em um corpo vivo". \\
\hline \multirow{3}{*}{04} & $\begin{array}{l}\text { a) Em formato de cordel, esta obra denuncia embates entre os lavradores e os fazendeiros } \\
\text { do Nordeste do Brasil. }\end{array}$ \\
\cline { 2 - 2 } b) “[...] todo cabra-da-peste/ ali se chama João/ Boa-Morte, vida não" são versos \\
\hline
\end{tabular}




\begin{tabular}{|c|c|}
\hline & consagrados deste cordel. \\
\hline \multirow[b]{2}{*}{05} & $\begin{array}{l}\text { a) No Brasil, o contexto da ditadura militar é o período compreendido em } 1964 \text { e } 1984 \text {, } \\
\text { quando militares assumiram a presidência do país. }\end{array}$ \\
\hline & $\begin{array}{l}\text { b) O contexto de enorme repressão política dessa época levou o poeta a escrever poemas } \\
\text { que denunciam a realidade de sua cidade e do país. }\end{array}$ \\
\hline \multirow[t]{2}{*}{06} & $\begin{array}{l}\text { a) Cabra marcado para morrer é um filme-documentário que conta com a narração de } \\
\text { Ferreira Gullar. }\end{array}$ \\
\hline & $\begin{array}{l}\text { b) Este filme-documentário dialoga com a denúncia social feita no poema "João Boa- } \\
\text { Morte cabra marcado pra morrer", escrito pelo autor. }\end{array}$ \\
\hline \multirow[t]{2}{*}{07} & $\begin{array}{l}\text { a) A denúncia social da condição do homem comum que enfrenta o desemprego e a } \\
\text { carestia da vida é tema central deste poema consagrado do autor. }\end{array}$ \\
\hline & $\begin{array}{l}\text { b) Um traço característico de alguns dos poemas do autor é seu tom panfletário, ou seja, } \\
\text { engajado em denunciar certos problemas sociais. }\end{array}$ \\
\hline \multirow[t]{2}{*}{08} & $\begin{array}{l}\text { a) Este disco de vinil - ou LP, como se chamava à época -, gravado em 1978, reúne } \\
\text { alguns dos principais poemas do autor, recitados por ele mesmo. }\end{array}$ \\
\hline & $\begin{array}{l}\text { b) O disco de vinil, conhecido simplesmente como vinil ou ainda Long Play (LP), é uma } \\
\text { mídia desenvolvida no final da década de } 1940 \text { para a reprodução de áudios. }\end{array}$ \\
\hline \multirow{2}{*}{09} & $\begin{array}{l}\text { a) O jabuti é o símbolo representado neste troféu, que premia, desde } 1959 \text {, os destaques } \\
\text { na área de literatura no Brasil. }\end{array}$ \\
\hline & $\begin{array}{l}\text { b) Ferreira Gullar foi agraciado com o Prêmio Jabuti em 2007, com a obra Resmungos } \\
\text { (ficção); em 2011, com Em alguma parte alguma (poesia). }\end{array}$ \\
\hline \multirow[t]{2}{*}{10} & $\begin{array}{l}\text { a) Publica, em 1976, Poema Sujo, que é um dos mais conhecidos livros do poeta, no qual } \\
\text { se misturam a vontade de relembrar o passado e a denúncia da limitação das liberdades } \\
\text { individuais. }\end{array}$ \\
\hline & $\begin{array}{l}\text { b) Neste livro-poema, o adjetivo sujo ganha múltiplas significações, explorando sentidos } \\
\text { denotativos e conotativos do termo. }\end{array}$ \\
\hline \multirow[t]{2}{*}{11} & $\begin{array}{l}\text { a) } \mathrm{Na} \text { obra de Ferreira Gullar, o tema da memória é constantemente explorado na } \\
\text { apresentação de experiências tanto individuais (do autor) quanto coletivas (do povo, do } \\
\text { país). }\end{array}$ \\
\hline & $\begin{array}{l}\text { b) Este recurso não verbal é usado constantemente em gêneros textuais como quadrinhos } \\
\text { para expressar algum pensamento, alguma lembrança ou imaginação de alguém. }\end{array}$ \\
\hline \multirow[b]{2}{*}{12} & $\begin{array}{l}\text { a) A música "Vambora", de Adriana Calcanhotto, faz uma famosa referência ao livro } \\
\text { Dentro da noite veloz, de Ferreira Gullar. }\end{array}$ \\
\hline & $\begin{array}{l}\text { b) Leitora assídua de poesia, a cantora e compositora gaúcha Adriana Calcanhotto já } \\
\text { musicou versos de poetas, lançou o disco A fábrica do poema, apresentou o programa } \\
\text { Poesia e movimento na TV e ilustrou poemas para uma antologia infantil. }\end{array}$ \\
\hline \multirow{2}{*}{13} & $\begin{array}{l}\text { a) Este conhecido poema de Ferreira Gullar já foi cantado por nomes da música brasileira } \\
\text { como Raimundo Fagner e Chico Buarque. }\end{array}$ \\
\hline & $\begin{array}{l}\text { b) Apesar de o título sugerir que vai explicar algo, este poema surpreende por apresentar } \\
\text { um complicado conflito existencial que todos nós enfrentamos. }\end{array}$ \\
\hline \multirow[t]{2}{*}{14} & $\begin{array}{l}\text { a) "O Trenzinho do Caipira" é uma composição musical de Heitor Villa-Lobos e parte } \\
\text { integrante da peça Bachianas Brasileiras } n^{o} \text { 2. A obra se caracteriza por imitar o } \\
\text { movimento de uma locomotiva com os instrumentos de uma orquestra. }\end{array}$ \\
\hline & $\begin{array}{l}\text { b) Muitos anos depois de sua composição original sem letra, "O Trenzinho do Caipira", } \\
\text { de Villa-Lobos, recebeu a letra com versos do "Poema Sujo", de Ferreira Gullar. }\end{array}$ \\
\hline
\end{tabular}

Fonte: ? Fonte: elabora para pesquisa

Assim, sem afetar a pontuação do jogador (dada por -2 pontos por par errado e +4 pontos por par correto), ao clicar no símbolo da lupa (Fig. 3), ele entra no modo espião, acessando as "Dicas" associadas às imagens por ele visualizadas. Uma vez nesse modo, o jogador poderá associar textos diferentes que se relacionam, de alguma maneira, à mesma imagem de um par correto no jogo da memória. Para testar se a suposição do jogador está correta, basta clicar no ícone da lupa novamente e sair do modo espião. 
Figura 3 - Representação do modo espião

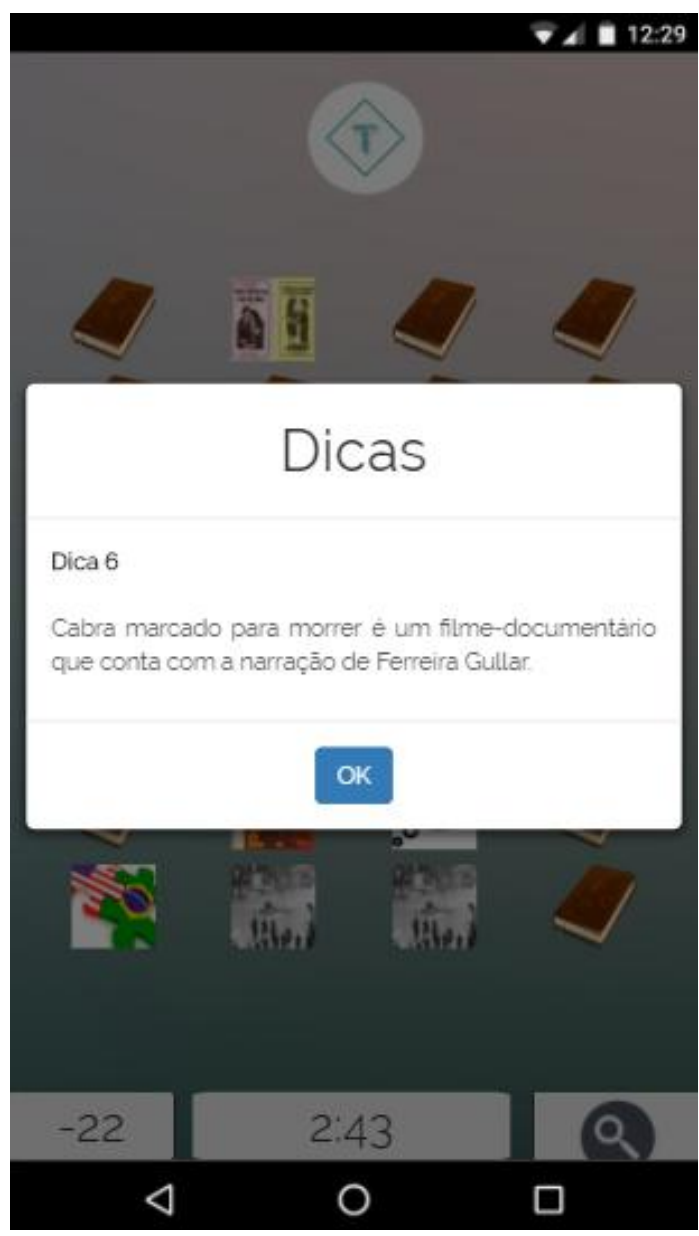

Fonte: acervo da pesquisa

A exploração dessas "Dicas" pelo professor condutor das aulas em que o jogo TURVO for utilizado como ferramental pedagógico resultará, se conduzida de forma adequada, a uma reflexão sobre o quão extenso pode ser o espaço de interferência que a produção de um autor pode gerar em uma determinada sociedade, considerando as múltiplas linguagens que dialogam com o universo literário na produção de uma rede de significações dos autores e das obras.

Por se tratar de um jogo, não se pode desconsiderar a importância de impor, ao jogador, certos desafios. Nesses termos, a fim de tornar o TURVO mais desafiador, pode ser estipulado um tempo máximo de 5 minutos para que o jogador consiga finalizar a partida. Caso não consiga, as cartas serão novamente embaralhadas e viradas ao avesso, dando início a um novo período para que o usuário complete a tarefa de encontrar os catorze pares de carta correspondentes. Se o usuário completar os pares dentro do limite imposto, ele é redirecionado para uma página com um "Prêmio" (Fig. 4), o qual será conquistado apenas se um jogador conseguir alcançar certa pontuação 


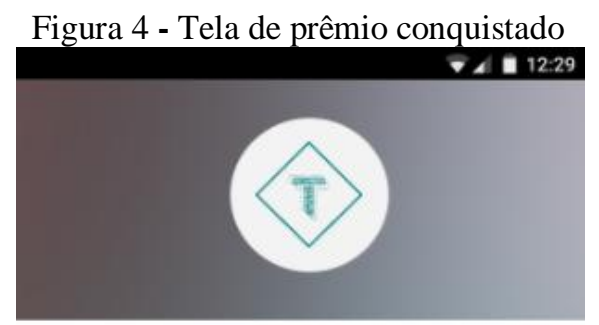

\title{
Parabéns! Olha o que você desbloqueou:
}

\author{
Papel de parede nivel 1
}

\section{$\triangleleft$

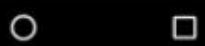

Fonte: ?

Composta por dois prêmios, que são, na verdade, dois papéis de parede com imagens do escritor maranhense (os quais se alternam na exposição para o jogador), esta seção resgata, quando alcançada pelo usuário, uma música cuja letra consiste no poema "Cantiga pra não morrer", de Ferreira Gullar, cantada por um artista do mesmo estado que o poeta, destacando o falar local e uma expressividade por meio dos famosos tambores do Maranhão. Mais uma vez, o esperado é que o professor utilize esses recursos do jogo para promover a construção/ampliação dos conhecimentos do alunado acerca da obra de um dos mais relevantes escritores brasileiros e de toda a rede de artefatos artístico-culturais e de conhecimento histórico e social que Ferreira Gullar fez surgir.

\section{Considerações finais}

Ao discutirem o papel dos jogos digitais como geradores de uma possibilidade de mudança nas abordagens pedagógicas cristalizadas pelo ensino formal, Paula e Valente (2016) advertem para o fato de que, em muitos casos, a inserção dos jogos no campo da educação tem dado ênfase à propriedade motivadora desses artefatos principalmente os digitais - em detrimento de suas várias outras contribuições para a promoção de um ensino de qualidade. Alinhando-nos com essa advertência feita pelos autores, buscamos, neste texto, dar visibilidade às múltiplas possibilidades que um jogo digital instaura para a formação do leitor crítico de textos literários que se deseja como egresso da escola de nível médio brasileira, sem ocultar, contudo, a centralidade do 
professor na mediação entre os jovens estudantes do Ensino Médio e a arte poética de Ferreira Gullar.

Assim, não se verificou, ao longo da apresentação aqui feita, uma exaltação da capacidade do TURVO de prender a atenção do aluno jogador, como seria costumeiro em um texto que analisa um artefato digital acionado como recurso pedagógico. O que se viu nestes escritos foi um esforço empreendido para evidenciar como, por meio da intervenção docente, um jogo digital pode se constituir como uma ferramenta potencializadora do acionamento dos diversos modos de ler empregados nos desenhos sociais hoje vigentes. Exatamente por isso, optou-se por uma exposição centrada em operações a serem feitas pelo professor de Língua Portuguesa no contexto de aproximação entre cultura literária e uso das tecnologias, constantemente postas como inconciliáveis.

Daí, portanto, que, neste texto, mesmo sendo ele acerca das possibilidades pedagógicas geradas por um artefato digital, a atuação docente do formador de leitores críticos de textos literários não foi ignorada. Em perspectiva oposta à anulação do docente em favor da exaltação do artefato tecnológico, o que buscamos foi reiterar a importância do professor na condução dos processos de formação literária do leitor jovem em contexto escolar. Não se tratou de uma opção que corrobora a visão tradicional que aposta na unilateralidade de perspectiva docente na construção dos sentidos do texto literário. Tratou-se, sim, de uma forma de destacar que é possível, fundamentando-se em uma perspectiva hoje cara ao ensino de língua materna, promover uma aproximação entre a cultura literária e a cultura digital/tecnológica, almejando uma formação adequada do estudante de Ensino Médio, por meio da mediação docente.

Acredita-se que, com isso, o presente texto poderá servir como propulsor do desenvolvimento de pesquisas e ações que resultem em jogos digitais os quais, como o mencionado aqui, confirmem que as aproximações e proposições pedagógicas até bem pouco tempo inimagináveis são, agora, uma possibilidade.

\section{Referências}

ANTUNES, Celso. Como desenvolver as competências em sala de aula. 2. ed. Petrópolis: Vozes, 2001.

AZEVEDO, Fernando; BALÇA, Ângela (coords.). Leitura e educação literária. Lisboa: Pactor, 2016.

BACHA, Edmar Lisboa; SCHWARTZMAN, Simon (orgs.). Brasil: a nova agenda social. Rio de Janeiro: LTC, 2011.

BERTUCCI BARBOSA, J.; VIEIRA BARBOSA, M. (orgs.). Leitura e mediação: reflexões sobre a formação do professor. Campinas, SP: Mercado das Letras, 2013.

BORTONI-RICARDO, Stella Maris; MACHADO, Veruska Ribeiro; CASTANHEIRA, Salete Flores. Formação do professor como agente letrador. São Paulo: Contexto, 2010.

BRASIL. Ministério da Educação. Base Nacional Comum Curricular. Brasília: Ministério da Educação, Secretaria de Educação Básica, 2018. 
BRASIL. Ministério da Educação. Secretaria de Educação Média e Tecnológica. Parâmetros Curriculares Nacionais: Ensino Médio. Brasília: Ministério da Educação, 1999.

BRASIL. Ministério da Educação. Secretaria de Educação Básica. PCNEM+ Ensino Médio: Orientações Educacionais Complementares aos Parâmetros Curriculares Nacionais. Linguagens, Códigos e suas Tecnologias. Brasília: Ministério da Educação, 2002.

BRASIL. Ministério da Educação. Secretaria de Educação Básica. Orientações curriculares para o Ensino Médio. Linguagens, Códigos e suas Tecnologias. Brasília: Ministério da Educação, 2006.

COSSON, Rildo. Letramento literário: teoria e prática. São Paulo: Contexto, 2014.

COSSON, Rildo. Letramento literário: uma localização necessária. Revista Letras e Letras. v. 31, n. 13, jul./dez. 2015. p. 173-187.

DELORS, Jacques. Educação: um tesouro a descobrir. In: RELATÓRIO PARA A UNESCO DA COMISSÃO INTERNACIONAL SOBRE A EDUCAÇÃO PARA O SÉCULO XXI. 5. ed. Tradução de José Carlos Eufrázio. São Paulo: Cortez; Brasília, DF: MEC: UNESCO, 2001.

DELORS, Jacques (org.). A educação para o século XXI: questões e perspectivas. Tradução de Fátima Murad. Porto Alegre: Artmed, 2005.

DINIZ-PEREIRA, Júlio Emílio. As licenciaturas e as novas políticas educacionais para a formação docente. Educação \& Sociedade, Ano XX, n. 68, dez. 99.

DINIZ-PEREIRA, Júlio Emílio. Formação de professores: pesquisa, representações e poder. 2. ed. Belo Horizonte: Autêntica, 2006.

DUKE, N. K.; PEARSON, P. D. Effective practices for developing reading comprehension. In: FARSTRUP, A. E.; SAMUELS, S. J. (orgs.). What research has to say about reading instruction. 3. ed. Newark: Internacional Reading Association, 2002. p. 205-242.

ECO, Umberto. Os limites da interpretação. 2. ed. Tradução de Pérola de Carvalho. São Paulo: Perspectiva, 2008.

GALVÃO, André Luís Machado; SILVA, Antônio Carvalho da. O ensino de literatura no Brasil: desafios a superar em busca de práticas mais eficientes. Revista Letras \& Letras. Uberlândia, v. 33, n. 2, jul./dez. 2017. p. 209-228.

GERALDI, J. W. Leitura e mediação: reflexões sobre a formação do professor. Campinas: Mercado de Letras, 2013.

GULLAR, Ferreira. Poema sujo. 8. ed. Rio de Janeiro: José Olympio, 2001. 
JONASSEN, D. H. Instructional Design Models for Well-Structured and Ill- Structured Problem-Solving Learning Outcomes. Educational Technology Research and Development, 45(1), 65-94. 1997.

JONASSEN, D. H. Computadores, ferramentas cognitivas: desenvolver o pensamento crítico nas escolas. Porto: Porto Editora. 2007.

JONASSEN, D. H.; CAMPBELL, J. P.; DAVIDSON, M. E. Learning with media: restructuring the debate. Educational Technology Research and Development, 42 (2), 31-39. 1994.

KATO, M. O aprendizado da leitura. São Paulo: Martins Fontes, 1985.

KLEIMAN, Angela. Oficina de leitura: teoria e prática. 6. ed. São Paulo: Pontes, 1998.

KLEIMAN, Angela. Texto e leitor: aspectos cognitivos da leitura. Campinas, SP: Pontes, 2002.

KOCH, Ingedore G. V. Desvendando os segredos do texto. 6. ed. São Paulo: Cortez, 2009.

$\mathrm{KOCH}$, Ingedore Villaça; ELIAS, Vanda Maria. Ler e compreender: os sentidos do texto. São Paulo: Contexto, 2007.

LEAHY-DIOS, Cyana. Educação literária como metáfora social: desvios e rumos. Niterói: EDUFF, 2000.

PAULA, Bruno Henrique de; VALENTE, José Armando. Jogos digitais e educação: uma possibilidade de mudança da abordagem pedagógica no ensino formal. Revista Ibero-americana de Educação. v. 70, n. 1 (15/01/16), p. 9-28.

PEREIRA, Vera Wannmacher; SANTOS, Thais Vargas dos. Estratégia de leitura de predição na escola: uso e consciência linguística no seu uso. Linguagem em (Dis)curso - LemD, Tubarão, SC, v. 17, n. 3, p. 361-380, set./dez. 2017.

PINHEIRO, Helder. Reflexões sobre o livro didático de literatura. In: BUZEN, Clécio; MENDONÇA, Márcia (orgs). Português no ensino médio e formação do professor. São Paulo: Parábola Editorial, 2006. p. 102-116.

ROJO, Roxane; MOURA, Eduardo. Multiletramentos na escola. São Paulo: Parábola Editorial, 2012.

SANTOS, Rodrigo Alves dos. Cartografando a construção do atual perfil de leitor de textos literários egresso das aulas de língua portuguesa do ensino médio. Revista Brasileira de Educação, v. 22, n. 71, 2017a. Disponível em: http://bit.ly/2AAQZcr. Acesso em: 13 nov. 2019.

SANTOS, Rodrigo Alves dos. "Conhecendo o perfil do jovem demandado pelo discurso oficial sobre o "novo" ensino médio. In: FRAGA, Fernando Caramuru B.; ROSA, José 
Henrique A.; ARÃO, Lílian. Dez olhares sobre juventude e cultura. Belo Horizonte: Fundação Guimarães Rosa, 2011. p.75-87.

SANTOS, Rodrigo Alves dos. Do professor de literatura ao formador de leitores críticos de textos literários: um estudo sobre a (re)invenção do professor de língua portuguesa para o trabalho com a leitura literária no ensino médio. 199f. Tese (Doutorado em Educação) - Faculdade de Educação - Universidade Federal de Minas Gerais, MG, 2009.

SANTOS, Rodrigo Alves dos. O caráter continuísta do discurso oficial sobre configuração de um sujeito docente para o trabalho com a leitura literária no ensino médio do século XXI. Revista Remate de Males (34-2), jul./dez. 2014. Campinas, SP. p. 421-441.

SANTOS, Rodrigo Alves dos. Para uma abordagem do texto literário no ensino médio alinhada com as demandas contemporâneas da educação formal. In: SOUSA, Ivan Vale de (org.). Leitura na educação básica: perspectivas e desafios. Jundiaí: Paco Editorial, 2017b. p. 115- 132.

SANTOS, Rodrigo Alves dos; BECHELANE, Maria Júlia Silva; SILVA, Orlando Enrico Liz Silvério. Jogos digitais como possibilidade de promoção do letramento literário: uma aplicação da pedagogia dos multiletramentos. Revista Mosaicum, 27, jan./jun. 2018. p. 35-48.

SOLÉ, I. Estratégias de leitura. 6. ed. Porto Alegre: Artmed, 1998.

Recebido em 01 de março de 2020

Aceito em 29 de maio de 2020 